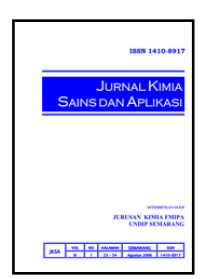

\title{
Adsorpsi Ion Logam Mg(II) Menggunakan Kitosan Termodifikasi Asam Askorbat
}

\author{
Wawan Prasetyo ${ }^{\text {a }}$, Khabibi ${ }^{a^{*}}$, Didik Setiyo Widodo ${ }^{\text {a }}$ \\ a Analytical Chemistry Laboratory, Chemistry Department, Faculty of Sciences and Mathematics, Diponegoro University, Jalan Prof. \\ Soedarto, Tembalang, Semarang \\ * Corresponding author: khabibi@live.undip.ac.id
}

Article Info

Keywords:

Chitosan, adsorption, chitosan-ascorbic acid, $\mathrm{Mg}(\mathrm{II})$
Kata Kunci:

Kitosan, adsorpsi, kitosan-asam askorbat, $\mathrm{Mg}(\mathrm{II})$

\section{Abstract}

The modification of chitosan-ascorbic acid and its utilization as an adsorbent of $\mathrm{Mg}$ (II) metal ions, metal ions $\mathrm{Cd}(\mathrm{II})$, and $\mathrm{Mg}$ (II)-Cd(II) metal alloys, also determination of $\mathrm{pH}$ and optimum contact time for adsorption of $\mathrm{Mg}$ (II), as well as knowing the ability of adsorption of ascorbic acid-ascorbic acid to $\mathrm{Mg}$ (II) ion has been conducted. The research stages consisted of determining the degree of deacetylation of the initial chitosan, the re-deacetylation process, and the determination of the degree of deacetylation of chitosan from the re-deacetylation results using FTIR. After that the re-deacetylated chitosan was modified using ascorbic acid and analyzed using FTIR and SEM. Chitosanascorbic acid was used to determine the $\mathrm{pH}$ and optimum contact time of adsorption on $\mathrm{Mg}$ (II) metal ions and their ability as adsorbents in $\mathrm{Mg}$ (II), $\mathrm{Cd}$ (II) metal ions and $\mathrm{Mg}$ (II)$\mathrm{Cd}(\mathrm{II})$. It was found that $\mathrm{pH}$ and optimum contact time of adsorption of ascorbic acidascorbic acid to $\mathrm{Mg}$ (II) metal ion was at $\mathrm{pH} 5$ and contact time of 12 hours. The adsorption ability of $\mathrm{Mg}$ (II) metal ion test was $24.66 \mathrm{mg} / \mathrm{g}$, Cd(II) equal to $24.71 \mathrm{mg} / \mathrm{g}$ and the adsorption capacity of acid-ascorbic chitosan on $\mathrm{Mg}(\mathrm{II})$ and $\mathrm{Cd}(\mathrm{II})$, obtained $\mathrm{Mg}$ (II) of $24.45 \mathrm{mg} / \mathrm{g}$, Cd(II) of $24.61 \mathrm{mg} / \mathrm{g}$.

\section{Abstrak}

Modifikasi kitosan-asam askorbat dan pemanfaatannya sebagai adsorben ion logam $\mathrm{Mg}(\mathrm{II})$, ion logam $\mathrm{Cd}(\mathrm{II})$, dan campuran ion logam $\mathrm{Mg}(\mathrm{II})-\mathrm{Cd}(\mathrm{II})$, juga dilakukan penentuan $\mathrm{pH}$ dan waktu kontak optimum untuk adsorpsi ion $\mathrm{Mg}$ (II), serta mengetahui kemampuan adsorpsi kitosan-asam askorbat terhadap ion $\mathrm{Mg}$ (II) telah dilakukan. Tahapan penelitian terdiri dari penentuan derajat deasetilasi dari kitosan awal, proses re-deasetilasi, dan penentuan derajat deasetilasi kitosan dari hasil re-deasetilasi menggunakan FTIR. Setelah itu kitosan hasil re-deasetilasi dimodifikasi menggunakan asam askorbat dan dianalisis menggunakan FTIR dan SEM. Kitosan asam-askorbat digunakan untuk menentukan $\mathrm{pH}$ dan waktu kontak optimum adsorpsi terhadap ion logam $\mathrm{Mg}$ (II) serta kemampuannya sebagai adsorben pada ion logam $\mathrm{Mg}$ (II), Cd(II), dan campuran ion logam $\mathrm{Mg}(\mathrm{II})-\mathrm{Cd}(\mathrm{II})$. Ditemukan bahwa $\mathrm{pH}$ dan waktu kontak optimum adsorpsi kitosan-asam askorbat terhadap ion logam $\mathrm{Mg}$ (II) yaitu pada $\mathrm{pH} 5$ dan waktu kontak 12 jam. Kemampuan adsorpsi pada uji ion logam $\mathrm{Mg}$ (II) sebesar 24,66 mg/g, Cd(II) sebesar $24,71 \mathrm{mg} / \mathrm{g}$ serta kemampuan adsorpsi kitosan asam-askorbat pada uji campuran ion logam $\mathrm{Mg}$ (II) dan Cd(II), didapatkan $\mathrm{Mg}$ (II) sebesar 24,45 mg/g, Cd(II) sebesar $24,61 \mathrm{mg} / \mathrm{g}$. 


\section{Pendahuluan}

Logam berat merupakan salah satu sumber pencemar bagi lingkungan hidup. Magnesium merupakan salah satu logam berat esensial yang menjadi bahan pencemar dalam sistem perairan. $\mathrm{Mg}$ (II) dalam tubuh manusia tidak terbiodegradasi, sehingga dapat terakumulasi dalam organ-organ tubuh manusia. Adsorpsi merupakan salah satu metode penghilangan logam berat yang sering digunakan karena lebih efektif, murah, dan efisien [1]. Kitosan adalah senyawa turunan kitin yang merupakan salah satu adsorben polimer organik yang melimpah di alam. Keberadaan gugus amina $\left(\mathrm{NH}_{2}\right)$ dalam kitosan menjadikan kitosan sebagai adsorben yang mampu mengikat logam berat [2]. Dalam beberapa tahun terakhir, perhatian telah difokuskan pada berbagai adsorben yang mampu mengikat logam untuk menghilangkan logam berat yang tidak diinginkan dalam air yang terkontaminasi [3]. Salah satu cara untuk mengatasi masalah tersebut yaitu dengan memodifikasi kitosan secara fisik maupun kimia [4]. Pada penelitian ini dicoba untuk memanfaatkan kitosan sebagai adsorben selektif ion logam $\mathrm{Mg}$ (II) dengan memodifikasi menggunakan asam askorbat. Dalam penelitian ini dipilih modifikasi menggunakan asam askorbat karena merupakan bahan kimia yang tidak beracun, lebih ekonomis, dan mudah didapat serta sebagai elemen yang dibutuhkan oleh manusia. Penelitian ini bertujuan memodifikasi kitosan-asam askorbat dan pemanfaatannya sebagai adsorben ion logam tunggal $\mathrm{Mg}(\mathrm{II})$, ion logam $\mathrm{Cd}(\mathrm{II})$, dan campuran ion logam $\mathrm{Mg}$ (II) dan Cd(II), menentukan $\mathrm{pH}$ dan waktu kontak optimum adsorpsi ion $\mathrm{Mg}$ (II).

\section{Metode Penelitian}

\section{Bahan}

Kitosan (teknis), $\mathrm{NaOH}$ (Merck) p.a, $\mathrm{CH}_{3} \mathrm{COOH}$ (Merck) p.a, Asam askorbat, Etanol, Eter, Glutaraldehid, $\mathrm{HCl}$ (Merck) p.a, $\mathrm{MgSO}_{4} .7 \mathrm{H}_{2} \mathrm{O}$ (Merck) p.a, $3 \mathrm{CdSO}_{4 .} 8 \mathrm{H}_{2} \mathrm{O}$ (Merck) p.a

\section{Re-deasetilasi Kitosan}

Serbuk kitosan seberat $30 \mathrm{~g}$ direndam dalam 600 mL NaOH 50\% kemudian dilakukan pengadukan dengan pengaduk magnetik selama 4 jam pada suhu $1200^{\circ} \mathrm{C}$. Residu dan filtrat dipisahkan dengan penyaringan, kemudian residu dinetralkan melalui pencucian dengan akuades sampai $\mathrm{pH}$ netral. Residu dikeringkan dalam oven dengan suhu $800^{\circ} \mathrm{C}$ selama 24 jam. Kitosan yang telah diredeasetiilasi diuji derajat deasetilasinya dengan FTIR.

\section{Pembuatan Kitosan Termodifikasi Asam Askorbat}

Serbuk kitosan sebanyak 10 g dilarutkan dalam 250 mL larutan asam asetat $2 \%$ kemudian diaduk dengan pengaduk magnetik sampai menjadi homogen, campuran tersebut menghasilkan larutan kental yang selanjutnya diteteskan dalam larutan $\mathrm{NaOH} 1 \mathrm{M}$ dengan diameter butiran yang seragam. Setelah 24 jam kontak dengan $\mathrm{NaOH}$, gel kitosan yang didapat dicuci dengan air demineralisasi sampai $\mathrm{pH}$ netral. Selanjutnya direndam dalam larutan asam askorbat 0,5\% selama 24 jam, hasil yang didapat dicuci dengan aquades, kemudian dikeringkan sampai tercapai berat konstan. Kemudian dilakukan pengujian dengan FTIR.

\section{Karakterisasi Kitosan Termodifikasi Asam Askorbat}

Spektra pada kitosan awal, kitosan re-deasetilasi, dan kitosan-tripolifosfat diperoleh dengan menggunakan Fourier Transform Infrared (FTIR) Shimadzu 820 IPC. Kitosan-tripolifosfat diuji analisis menggunakan Scanning Electron Microscopy (SEM) JSM 6360LA.

\section{Pengaruh pH Terhadap Adsorpsi Mg(II)}

Larutan $\mathrm{Mg}$ (II) dengan konsentrasi 0,02 M, volume $25 \mathrm{~mL}$ diatur keasamannya pada $\mathrm{pH} 2,3,4,5,6$, dan 7 dengan menggunakan larutan $\mathrm{HCl}$ dan $\mathrm{NaOH}$. Selanjutnya dimasukkan ke dalam erlenmeyer $250 \mathrm{ml}$ yang telah berisi $0,1 \mathrm{~g}$ kitosan-asam askorbat. Selanjutnya digojog dengan kecepatan 250 rpm selama 24 jam, disaring dan filtrat yang diperoleh dianalisis menggunakan SSA.

\section{Pengaruh Waktu Kontak Terhadap Adsorpsi Mg(II)}

Larutan $\mathrm{Mg}$ (II) dengan konsentrasi 0,02 M, volume $25 \mathrm{~mL}$ pada $\mathrm{pH}$ optimum, selanjutnya dimasukkan ke dalam erlenmeyer $250 \mathrm{ml}$ yang telah berisi $0,1 \mathrm{~g}$ kitosan-asam askorbat. Masing-masing erlenmeyer digojog dengan kecepatan 250 rpm selama 3 jam, 6 jam, 9 jam, 12 jam, dan 15 jam, disaring dan filtrat yang diperoleh dianalisis menggunakan SAA.

\section{Adsorpsi Ion Mg(II) Dalam Larutan Ion Logam Tunggal Mg(II) dan Cd(II)}

Sebanyak 0,1 g kitosan-asam askorbat cetakan $\mathrm{Mg}$ (II) ditambahkan ke dalam $25 \mathrm{ml}$ larutan sulfat mengandung ion logam $\mathrm{Mg}$ (II) $100 \mathrm{ppm}$ pada $\mathrm{pH}$ dan waktu kontak optimum. Larutan diaduk sesuai $\mathrm{pH}$ dan waktu optimum pada $250^{\circ} \mathrm{C}$, dan dilakukan penyaringan. Filtrat yang diperoleh dianalisis dengan SSA. Proses diulang dengan menggunakan $25 \mathrm{~mL}$ larutan sulfat mengandung ion logam Cd(II) 0,02M.

\section{Adsorpsi Ion $\mathrm{Mg}(\mathrm{II})$ Dalam Larutan Campuran Ion $\mathrm{Mg}$ (II) dan Cd(II)}

Sebanyak 0,1 g kitosan-asam askorbat cetakan $\mathrm{Mg}$ (II) ditambahkan ke dalam $25 \mathrm{ml}$ larutan sulfat mengandung ion logam $\mathrm{Cd}(\mathrm{II})$ dan $\mathrm{Mg}$ (II) $100 \mathrm{ppm}$. Larutan diaduk sesuai $\mathrm{pH}$ dan waktu kontak optimum pada $250^{\circ} \mathrm{C}$, dan lakukan penyaringan. Filtrat yang diperoleh dianalisis dengan SSA.

\section{Hasil Dan Pembahasan}

\section{Penentuan Derajat Deasetilasi Kitosan Awal}

Kitosan dianalisis menggunakan spektroskopi FTIR untuk mengetahui gugus fungsi dan menghitung derajat deasetilasi kitosan dengan menggunakan metode Base Line [5]. Spektra FTIR dari kitosan dapat dilihat pada gambar 1. 


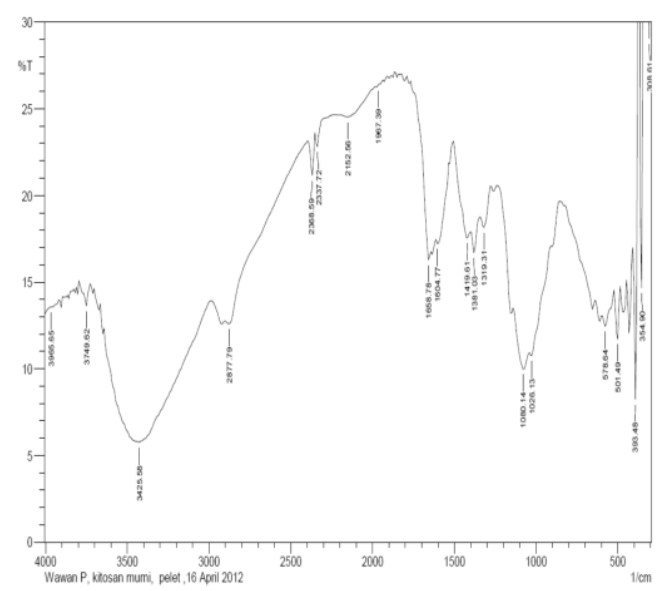

Gambar 1. Spektra FTIR Kitosan Awal

Penentuan derajat deasetilasi kitosan dilakukan untuk mengetahui persen gugus asetil yang telah hilang dari struktur kitin dan digantikan oleh gugus amina. Semakin tinggi derajat deasetilasi kitosan, maka gugus asetil yang terdapat dalam kitosan tersebut semakin sedikit dan semakin banyak aminanya [6].

Tabel 1. Bilangan gelombang dan prediksi gugus fungsi yang ada pada spektra FTIR kitosan

\begin{tabular}{|c|c|}
\hline $\begin{array}{c}\text { Bilangan gelombang } \\
\left(\mathrm{cm}^{-1}\right)\end{array}$ & Prediksi gugus fungsi \\
\hline 3425,58 & Uluran OH dan uluran $\mathrm{NH}$ \\
\hline 2877,79 & Uluran C-H \\
\hline 1658,78 & $\mathrm{~N}-\mathrm{H}$ tekuk \\
\hline $1381,03 \& 1319,31$ & Uluran C-N dan OH tekuk \\
\hline $1080,14 \& 1033,85$ & Uluran C-O \\
\hline
\end{tabular}

Dari tabel 1 sesuai dengan gugus fungsi khas kitosan, yang menunjukkan bahwa kitosan yang diperoleh memiliki puncak pada $3425,58 \mathrm{~cm}^{-1}$ yang mengindikasikan adanya uluran $\mathrm{OH}$ dan $\mathrm{NH}$ serta gugus $\mathrm{N}-\mathrm{H}$ tekuk ditunjukkan pada 1658,78 . Dari perhitungan diperoleh derajat deasetilasi kitosan awal sebesar $69,85 \%$.

\section{Re-deasetilasi Kitosan}

Re-deasetilasi kitosan dilakukan untuk meningkatkan derajat deasetilasi kitosan awal. Reaksi deasetilasi pada dasarnya merupakan suatu reaksi hidrolisis gugus amida $\left(-\mathrm{NHCOCH}_{3}\right)$ menggunakan larutan basa. Proses deasetilasi menyebabkan hilangnya gugus asetil $\left(-\mathrm{COCH}_{3}\right)$ melalui pemutusan ikatan antara karbon dan nitrogen pada gugus amida. Kitosan hasil proses re-deasetilasi kemudian diuji kembali menggunakan spektroskopi FTIR untuk mengetahui derajat deasetilasinya. Spektra FTIR hasil re-deasetilasi kitosan dapat dilihat pada gambar 2 .

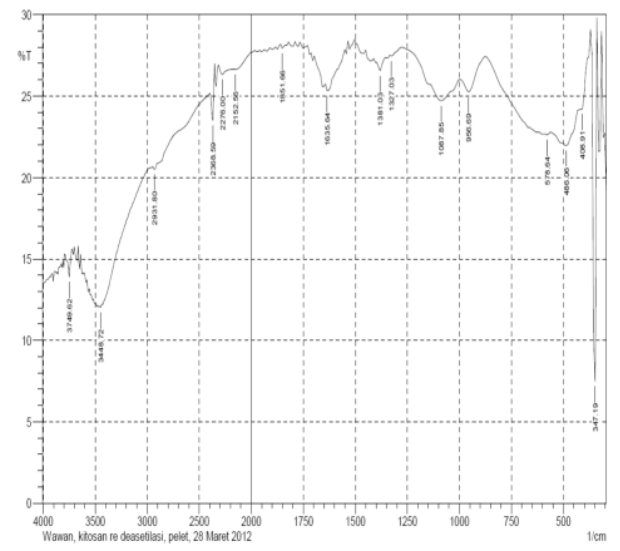

Gambar 2. Spektra FTIR re-deasetilasi kitosan

Dari gambar 2 gugus fungsi yang ada pada kitosan hasil re-deasetilasi tidak berbeda secara signifikan jika dibandingkan dengan kitosan murni sebelum dilakukan proses re-deasetilasi, yang membedakan yaitu adanya absorbansi pada uluran $\mathrm{O}-\mathrm{H}$ dan uluran $\mathrm{N}-\mathrm{H}$ dengan bilangan gelombang 3448,72 serta $\mathrm{N}-\mathrm{H}$ tekuk dengan bilangan gelombang 1635,64 yang mempunyai \% transmitasi lebih kecil. Nilai transmitasi yang lebih kecil menyebabkan absorbansi lebih besar, sebab transmitasi berbanding terbalik dengan absorbansi. Berdasarkan perhitungan diperoleh derajat deasetilasi sebesar $78,32 \%$. Derajat re-deasetilasi mengalami peningkatan sebesar $8,47 \%$ dibandingkan dengan derajat deasetilasi awal yang hanya sebesar $69,85 \%$.

\section{Pembuatan Kitosan Termodifikasi Asam Askorbat}

Tujuan modifikasi kitosan dengan asam askorbat adalah untuk menambah gugus aktif pada kitosan sehingga memperkuat sifat fisik dan mampu meningkatkan kemampuan kitosan dalam mengadsorpsi ion logam. Kitosan asam askorbat yang terbentuk kemudian dikarakterisasi menggunakan FTIR. Spektra FTIR hasil modifikasi kitosan dengan asam askorbat dapat dilihat pada gambar 3 .

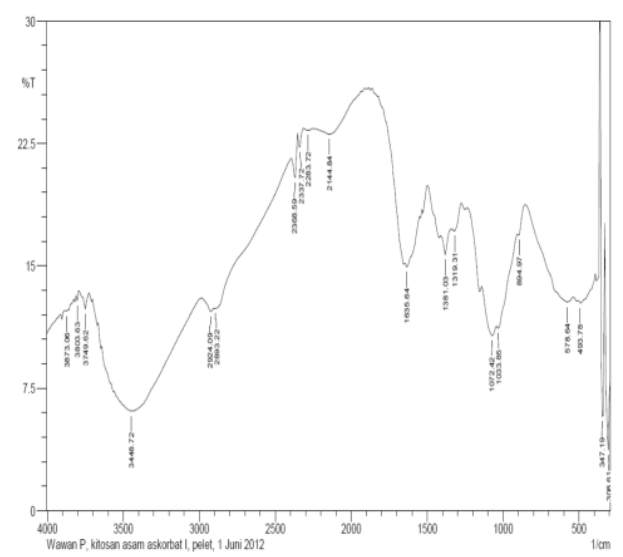

Gambar 3. Spektra FTIR kitosan- asam askorbat

Spektra FTIR kitosan-asam askorbat terdapat pada puncak 1635,64 $\mathrm{cm}^{-1}$ yang menunjukan gugus fungsi $\mathrm{C}=\mathrm{O}$ tekuk yang merupakan gugus fungsi pada asam askorbat, sehingga dapat diketahui bahwa asam askorbat telah terikat pada kitosan. 
Karakterisasi Kitosan Termodifikasi Asam Askorbat dengan Menggunakan Analisis SEM (Scanning Electron Microscopy)

Morfologi permukaan kitosan-asam-askorbat dapat dilihat menggunakan SEM. Berdasarkan citra SEM dengan perbesaran $3000 \mathrm{X}$ tersebut dapat dilihat morfologi kitosan-asam askorbat. Dikarenakan perbesaran yang kurang maka hanya dapat terlihat morfologi permukaan kitosan-asam askorbat tanpa adanya pori yang begitu jelas. Citra SEM kitosan-asam askorbat mempunyai morfologi yang memiliki beberapa pori. Adsorben dengan adanya pori memungkinkan kemampuan adsorpsinya lebih besar, sebab luas permukaan adsorbennya lebih besar. Hasil analisis SEM menggunakan perbesaran $3000 \mathrm{X}$ pada kitosan termodifikasi asam askorbat dapat dilihat pada gambar 4 berikut:

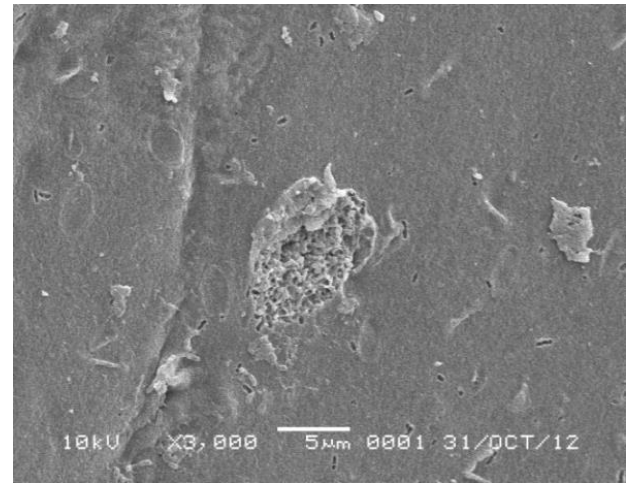

Gambar 4. Citra SEM Kitosan-Asam askorbat

Pengaruh pH Terhadap Adsorpsi Ion Logam Mg(II)

Pada gambar 5 menunjukkan hasil adsorbsi ion logam Mg(II). Pada pH 2 jumlah proton yang banyak sehingga akan terjadi kompetisi antara ion $\mathrm{H}+$ dengan ion $\mathrm{Mg}$ (II) yang menempati gugus amina $\left(-\mathrm{NH}_{2}\right)$ sehingga adsorpsi ion $\mathrm{Mg}$ pada kitosan-asam askorbat cetakan $\mathrm{Mg}$ (II) rendah. Pada $\mathrm{pH} 3$ dan $\mathrm{pH} 4$ terjadi peningkatan adsorpsi ion $\mathrm{Mg}^{2+}$ dan mencapai $\mathrm{pH}$ optimum pada $\mathrm{pH} 5$ dengan adsorpsi $\mathrm{Mg}$ (II) terbesar sebanyak 1232,29 mg/g, karena jumlah ion $\mathrm{H}^{+}$lebih rendah dibandingkan pada suasana $\mathrm{pH} 2$.

Sedangkan adsorpsi ion $\mathrm{Mg}$ (II) akan menurun pada pH 5 keatas, hal ini dikarenakan dengan bertambahnya $\mathrm{pH}$ maka jumlah ion $\mathrm{OH}^{-}$meningkat sehingga interaksi yang terjadi antara ion logam $\mathrm{Mg}(\mathrm{II})$ dengan ion $\mathrm{OH}^{-}$ semakin kuat. Pada penelitian ini, $\mathrm{pH}$ optimum adsorpsi ion $\mathrm{Mg}$ (II) terjadi pada $\mathrm{pH}$ 5, karena pada $\mathrm{pH} 5$ jumlah proton $\mathrm{H}^{+}$dan ion $\mathrm{OH}^{-}$di dalam larutan tidak terlalu banyak, sehingga ion $\mathrm{Mg}$ (II) dapat berikatan dengan adsorben dalam jumlah yang optimal.

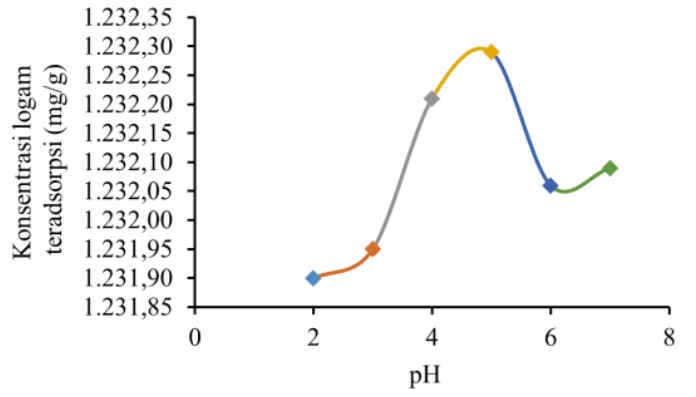

Gambar 5. Grafik Hubungan pH dengan Konsentrasi Ion Logam Mg Teradsorpsi (mg/g)

Pengaruh Waktu Kontak Terhadap Adsorpsi Ion Logam Mg(II)

Dari gambar 6 menunjukkan bahwa pada kitosanasam askorbat mengalami peningkatan adsorpsi ion $\mathrm{Mg}^{2+}$ yang sama secara signifikan yaitu pada waktu kontak 3, 6, dan 9 jam. Sedangkan waktu kontak optimum yang didapat yaitu pada waktu kontak 12 jam.

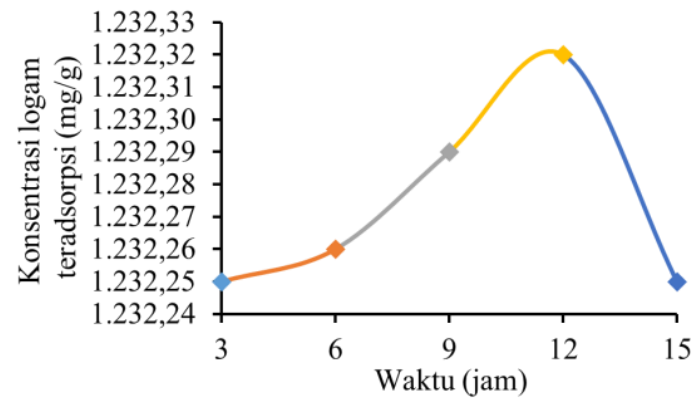

Gambar 6. Grafik Hubungan Waktu Kontak dengan Konsentrasi Ion Logam MgTeradsorpsi (mg/g)

\section{Uji Adsorpsi Ion $\mathrm{Mg}(\mathrm{II})$}

Uji adsorpsi terhadap ion $\mathrm{Mg}$ (II) di lakukan dengan adsorpsi pada larutan ion logam tunggal $\mathrm{Mg}$ (II) dan Cd(II), serta dilakukan pada larutan campuran ion logam $\mathrm{Mg}(\mathrm{II}), \mathrm{Cd}(\mathrm{II})$. Proses adsorpsi dilakukan pada waktu kontak optimum (12 jam) dan pH optimum $(\mathrm{pH}=5)$. Hasil uji adsorpsi pada ion logam tunggal dapat dilihat pada tabel 2.

Tabel 2: Uji adsorpsi ion $\mathrm{Mg}$ (II) pada larutan ion logam tunggal

\begin{tabular}{cc}
\hline Ion logam & $\begin{array}{c}\text { Ion logam yang teradsorpsi } \\
(\mathrm{mg} / \mathrm{g})\end{array}$ \\
\hline $\mathrm{Mg}(\mathrm{II})$ & 24,45 \\
$\mathrm{Cd}(\mathrm{II})$ & 24,71 \\
\hline
\end{tabular}

Tabel 2 menjelaskan bahwa adsorben kitosan-asam askorbat memiliki kemampuan adsorpsi yang sama bagusnya terhadap logam $\mathrm{Mg}$ (II) maupun $\mathrm{Cd}(\mathrm{II})$. Sedangkan hasil uji adsorpsi pada larutan campuran ion logam $\mathrm{Mg}(\mathrm{II})$, Cd(II) dapat dilihat pada tabel 3 sebagai berikut: 
Tabel 3: Uji adsorpsi ion $\mathrm{Mg}$ (II) pada larutan campuran ion logam $\mathrm{Mg}$ (II) dan Cd(II)

\begin{tabular}{cc}
\hline Ion logam & Ion logam yang teradsorpsi $(\mathrm{mg} / \mathrm{g})$ \\
\hline $\mathrm{Mg}(\mathrm{II})$ & 24,45 \\
$\mathrm{Cd}(\mathrm{II})$ & 24,61 \\
\hline
\end{tabular}

Tabel 3 menjelaskan bahwa adsorben kitosan-asam askorbat mempunyai kemampuan adsorpsi yang sama bagusnya terhadap ion logam $\mathrm{Mg}$ (II) dan Cd(II). Hasil yang ditunjukkan oleh tabel 2 dan 3 dapat terjadi, hal dikarenakan berbagai faktor yang mempengaruhi antara lain jari-jari ion logam, keelektronegatifan, dan dosis agen pengikat silang.

Ditinjau dari aspek fisik, jari-jari ion logam $\mathrm{Mg}$ (II) adalah 1,35 ̊̊ lebih besar jika dibandingkan dengan jarijari ion $\mathrm{Cd}(\mathrm{II})$ sebesar $0,92 \AA$, hal tersebut mengakibatkan ion logam Cd(II) yang akan lebih banyak teradsorpsi pada pori kitosan-asam askorbat. Keelektronegatifan ion $\mathrm{Mg}$ (II) 1,31 lebih rendah dibandingkan dengan keelektronegatifan ion Cd(II) 1,69 sehingga ion Cd(II) semakin mudah menarik elektron seperti $\mathrm{NH}_{3}{ }^{+}$. Peranan dosis agen pengikat silang berpengaruh terhadap kemampuan adsorpsi, dosis agen pengikat silang yang terlalu banyak menyebabkan gugus aktif pada kitosan terikat oleh asam askorbat yang berfungsi sebagai agen pengikat silang. Sehingga gugus aktif yang seharusnya dapat digunakan untuk mengikat ion logam tidak bisa mengikat ion logam. Hal ini mengakibatkan gugus aktif pada kitosan menjadi lebih sedikit sehingga kemampuan adsorpsi lebih rendah.

\section{Kesimpulan}

Telah dihasilkan modifikasi kitosan-asam askorbat sebagai adsorben. $\mathrm{pH}$ dan waktu kontak optimum adsorpsi kitosan-asam askorbat terhadap ion logam Mg(II) yaitu pada pH 5 dan waktu kontak 12 jam. Kemampuan adsorpsi pada uji ion logam tunggal $\mathrm{Mg}$ (II) sebesar 24,66 mg/g, Cd(II) sebesar $24,71 \mathrm{mg} / \mathrm{g}$ serta kemampuan adsorpsi kitosan asam-askorbat pada uji campuran ion logam $\mathrm{Mg}$ (II) dan $\mathrm{Cd}(\mathrm{II})$, didapatkan Mg(II) sebesar 24,45 mg/g, Cd(II) sebesar 24,61 mg/g.

\section{Daftar Pustaka}

[1] Mirjana Minceva, Liljana Markovska, Vera Meshko, Removal of $\mathrm{Zn} \mathrm{2+,} \mathrm{Cd} \mathrm{2+} \mathrm{and} \mathrm{Pb} 2+$ from binary aqueous solution by natural zeolite and granulated activated carbon, Macedonian Journal of Chemistry and chemical engineering, 26, 2, (2007) 125-134 http://dx.doi.org/10.20450/mjcce.2007.267

[2] Bimbing Herwanto, Eko Santoso, Adsorpsi Ion Logam $\mathrm{Pb}$ (II) pada Membran Selulosa Kitosan Terikat Silang, Akta Kimia Indonesia, 2, 1, (2006) 924

[3] Shengling Sun, Li Wang, Aiqin Wang, Adsorption properties of crosslinked carboxymethyl-chitosan resin with $\mathrm{Pb}(\mathrm{II})$ as template ions, Journal of Hazardous Materials, 136, 3, (2006) 930-937 http://dx.doi.org/10.1016/j.jhazmat.2006.01.033

[4] ES Dragan, MV Dinu, Removal of copper ions from aqueous solution by adsorption on ionic hybrids based on chitosan and clinoptilolite, Ion Exchange Lett, 2, (2009) 15-18

[5] Serkan Keleşoğlu, Comparative adsorption studies of heavy metal ions on chitin and chitosan biopolymers, İzmir Institute of Technology,

[6] Dietrich Knorr, Functional Properties of Chitin and Chitosan, Journal of Food Science, 47, 2, (1982) 593$595 \quad$ http://dx.doi.org/10.1111/j.13652621.1982.tb10131.x 